The International Journal Of Engineering And Science (IJES)

|| Volume || 6 || Issue || 3 || Pages || PP 116-121 || 2017 ||

ISSN (e): $2319-1813$ ISSN (p): $2319-1805$

\title{
E-Governance and the ICT Legislative Framework
}

\author{
Edison Wazoel Lubua \\ Institute of Accountancy Arusha P. O. Box 2798, Arusha, Tanzania
}

\begin{abstract}
-
This study assesses the effect of ICT policies and practices toward ensuring the governance supported by information sharing in Tanzania. Logically, the work is organized in four main categories. The first category introduces the study through providing the background, statement of the problem and objectives. This part is followed by a research method. The study was based on interpretive principles, and it used secondary data to arrive to its conclusions. The analysis is conducted through grouping elements, which responds to the same pattern of the study, under the same section. The last part of the study provides the conclusion and recommendations to the local legislative framework.
\end{abstract}

Keywords: ICT Legislative Framework, e-Governance, ICT Policies

Date of Submission: 02 March 2017

$\longrightarrow$ Date of Accepted: 27 March 2017

\section{BACKGROUND OF THE STUDY}

Tanzania believes in good governance. Its constitution acknowledges the government that comes to power through a free and fair election. Article 18(b) of the constitution ensures that citizens are empowered enough for decision making, through receiving and disseminating the information (Constitution of Tanzania, 1977). Similarly, since the government comes to power for the people, the same constitution defines the power of the government and how it must relate to people. Therefore, it is the constitutional role of the government to establish a democratic institution that values and advocates for the following pillars of good governance: These are transparency, participation and accountability (Lubua, 2014).

In modern societies (years after 2000), changes in technology simplify the way citizens participate in different government activities. It is because of this reason that Information and Communication Technologies (ICTs) are used to engage people in making decisions that impacts their everyday lives (Kiknadze, 2007; Nchunge, Sakwa, \& Mwangi, 2012). The use of ICTs in governance processes provides a platform for people to participate in decision making. The study cites the recent Tanzanian constitution formulation process as a valid example where ICT tools were used to receive opinions from citizens and other stakeholders (Bunge Maalumu la Katiba, 2013). The adoption of ICT tools for information sharing and governance decreases operation costs to the government, while allowing many citizens as possible to access services conveniently. The cost decreases because there is no cost for travelling and other related traditional operations.

The government allowing a recommended level of transparency in its operations is characterised by the society participating in decision making (Lubua, 2014). Transparency enables citizens to offer the right assessment about the performance of the government, which facilitates the process of decision making through the ballot (Janssen, 2012). Although the government of Tanzania understands that transparency is an important element of good governance, it is unfortunate that bureaucratic procedures and local legislations often block the extent to which citizens and other stakeholders access government information (Freedom House, 2010). This denies citizens the right to make government leaders accountable for decisions that they make.

In Tanzania, there are a number of efforts by the government in ensuring that citizens benefits from the use of ICTs. First, Tanzania links to the internet through the undersea Fibre Optic cables which provides the internet beyond the current needs (Kowero, 2012). Almost every region is connected to this network through the National ICT Backbone. Moreover, other efforts are observed in the area of local contents. Government agencies such as the E-Government Agency, the Tanzania Revenue Authority, the Tanzania Communication Regulatory Authority and the Recruitment Agency are doing better in terms of the content (Lubua, 2014). However, many government entities are still struggling with these basic steps of information sharing.

To those public institutions actively using ICTs in managing their operations, it is important to raise the awareness of beneficiaries to have a good return on investment (Janssen, 2012; Kowero, 2012)). The government needs to cooperate with other stakeholders through the use of news media, billboards, workshops, conferences and even traditional meetings to raise the level of awareness of stakeholders, on benefits attached to online services providedthrough its institutions. This study in interested at analysing legislations influencing the implementation of ICT supported governance. 


\section{STATEMENT OF THE RESEARCH PROBLEM}

The use of ICTs in government operations brings tangible advantages to the community (Tanzania ICT Policy, 2003). In governance, uses of ICT encourage accountability, transparency and participation (Lubua \&Maharaj, 2012). ICT tools increase the ability of citizens to access and share information while enhancing their knowledge about government operations (Lubua, 2014). More importantly, ICT tools are advantageous to vulnerable members of the society, because they facilitate information sharing at the low cost. Since uses of ICT create transparent working environments, citizens are able to put pressure to actors on the need to improve the performance and quality of services (Collaboration on International ICT Policy in East and Southern Africa, 2012). Moreover, transparent environment allows members of the society to enforce accountability to the government.

Citizens enjoy benefits of integrating ICTs in government operations in a number of ways. Such ways include participatory decision making and availability of services online. Together with these benefits, cases are reported where a number of ICT initiatives (projects) do not materialise (Lubua \&Maharaj, 2012). Citizens are facing difficulties to access their services, even in institutions with well-established systems. Also, many officials are not comfortable with the use of ICTs in processing the information that would respond to the needs of local citizens. Arguably, this impact the extent to which citizens are engaged in government activities. Could setbacks in the use of ICTs in enhancing good governance be associated with weaknesses in legislations and policies governing ICTs and related activities? It is the interest of this study to address this question.

\section{THE OBJECTIVE}

Generally, the study assesses the effect of ICT policies and practices toward the governance of people in Tanzania. Specifically, the study determines whether the Tanzanian legislations adequately support the use of ICTs in governance and civic participation. Also, the study determines the contribution of regional cooperation to the adoption of ICTs in governance.

\section{METHODOLOGY}

This study follows interpretive Principles, and was conducted in Tanzania. Moreover, it depended on secondary data to arrive to its conclusions. The study in meant for the local context, and generalisation is valid where there is a clear sharing of key legislative features. The following legislations were used: the National ICT Policy (2003), the E-Governance Strategy (2013), the Electronic and Postal Communication Act (2010), the Tanzania Communications Regulatory Authority Act (2003), the National Security Act (1970), and the Newspapers Act (1976). Moreover, the study used government and privately owned web-portals for sharing information to address parts of its objectives.

Generally, the study identified key aspects of the Tanzanian legislations, and used them in showing their impact in enhancing good governance. This impact is established through the use of the available literature. Furthermore, the discussion is based on the current user experience (according to available literature) and features of key online platforms.

\section{THE ICT LEGISLATIVE FRAMEWORK}

This section shows whether the Tanzanian ICT Legislative Framework adequately supports the use of ICT tools in governance activities. In this discussion, the National ICT Policy (2003) is given a special consideration because it forms the basis for success in ICT projects. It is the intention of the policy to use ICTs to attain sustainable developments in poverty reduction (Tanzania National ICT Policy, 2003). The desire to attain sustainable developments is aligned with the Tanzania Development Vision (2025); hence it gives the National ICT Policy a strategic landscape in promoting participation and openness in government activities for national developments.

Section 3.3.2 (a) of the National ICT Policy presents the plan of the government to create conducive environment for sustainable ICT industry in Tanzania (which includes internet accessibility). The study acknowledges efforts by the Tanzanian Ministry of Science and Technology in ensuring a reliable access to the internet by citizens. Regardless of present financial and technical constraints, the government developed a National ICT Backbone (NICTBB) that extends from Dar Es Salaam to Tanzania Mainland. The NICTBB covers about 10,000 kms, and extend to eight countries neighbouring Tanzania (Mbarawa, 2012). Arguably, the NICTBB is meant to enhance the efficiency and reliability of Internet services (Kowero, 2012). Currently, Tanzania is ranked as No 158 in the list of countries with their internet speed. The download speed is averagely $0.88 \mathrm{Mbps}$ and the upload speed is $0.43 \mathrm{Mbps}$ (oAfrica, 2012). This speed is lower than that of Kenya and Rwanda (within the same block) ranking No 87 and 88 respectively, in the world. Although the cost of internet access is relatively lower than the neighbouring countries, inadequate internet speed (to users) contributes to the low reliability of the medium in facilitating different transactions, including information sharing. 
Moreover, the Tanzanian legislation offers an incentive to the importation of computers and related accessories, through tax exemption (Value Added Tax Act, 2006). The exemption is an initiative to ensure that the Tanzanian population benefits from uses of computer technologies. Although people have enjoyed the tax exemption for about 8 years now, the per cent of internet usage is as low as 13.1\% (Internet Society, 2014). Again, the internet usage in Tanzania is lower than that of the neighbouring Kenya, which is about $32.1 \%$. The government of Kenya does not offer exemptions for the purchase of computers (Kenya-Value Added Tax Act, 2013). Arguably, this comparison suggests that the exemption of computer related accessories has not significantly influenced the use of the internet in Tanzania.

Furthermore, the government showed the intention to share its information with the public through section 10 $(1,2)$ of the Electronic and Postal Communication Act (CAP 306) of 2011. The article suggests the use of web addresses with the country code by private and public entities. However, this is not mandatory and does not address the challenge of poor local contents.

Generally, this study acknowledges efforts invested by the government to ensure that citizens benefits from the use electronic services in promoting national developments. However, the available stable National ICT Backbone, exemptions to the importation of computers and the presence of the National ICT Policy for above 10 years now, do not reflect the actual progress made in ICT usage for information sharing. Youth, women and other disadvantaged groups are less empowered because of low access to information facilities supported by the NICTBB. The study noted the following areas in the Tanzanian legislation to affect the pace of engaging people in the use of internet and other information facilities:

\section{(i) Poor Local Contents}

Section 3.3.3 (viii) of the National ICT Policy of 2013 acknowledges that the underdevelopment of local contents is among its challenges in the desire to utilise its infrastructure effectively. Because of this challenge, the policy enabled the government to establish the Agency (E-Government Agency) to oversee the implementation of its objectives. Amid the presence of this Agency, the Tanzanian government lacks a legislation governing the quality and standard of contents placed to its portals. The quality information in any website refers to the availability of the information meeting desires of users. This study found that a large number of public portals contain the information irrelevant to the need of their society. Websites are characterised by political activities rather than the actual services expected by stakeholders. Also, some of the information on these websites is out of date. Citizens have to go through a number of processes to get the information benefiting them. A good example is the website of the Ministry of Agriculture and Livestock; citizens expect information about the weather, pesticides and prices for crops to make a good use of the technology in agriculture. In between May and November 2014, the study observed that this information (and in some incidences the website itself) was completely unavailable.

\section{(ii) The Use of Foreign Languages in Local Contents}

Tanzania uses Swahili as the national language. It is obvious that many citizens are more comfortable to share different information through Swahili than English (Lubua, 2014). However, this study found that the Swahili language is lowly used in communications which involve use of ICTs, even for the public consumption. This study agrees with the assertion by section 3.9.3 (VI) of the National ICT Policy, which recognises that Swahili is lowly used in technological communications. Alternatively, both Swahili and English may be used to address the challenge of the language barrier. Currently, there are very few web portals where both Swahili and English languages are used. A good example is the e-government website and the Tanzania Government Portal. Uses of Swahili in local contents allow a broader availability of the message relevant to local people (Lupogo, 2014). Also, it offers citizens the opportunity to share the information more comfortably. The tendency of using foreign languages (especially English) only in government websites paralyses the ability of citizens to use such information for their development. In 2012, the highest level of education acquired by $81.7 \%$ of Tanzanians was the primary education (The United Republic of Tanzania, 2012). With this information, the percent of citizens who can follow the English language is lower than $20 \%$ of the whole population. In the presence of a legislation that governs the language use, it would be easy to monitor the performance in this area.

\section{(iii)Inadequate Coordination in the Implementation of Policy Objectives}

Currently, Tanzania uses the National ICT Policy adopted in 2003. The policy provides the outline of objectives that the nation wants to achieve through the use information technologies and associated services. Moreover, the Policy outlines strategies for achieving these objectives. These objectives guide the process for making managerial decisions by government executives, which influence the accomplishment of specified ICT projects (for citizens) within the time. Nevertheless, the policy implementation requires a proper coordination for effective results. It is on this basis that section 3.2.2 (g) of the National ICT Policy (2003) proposes the establishment of a mechanism (organ) to manage the implementation process of policy objectives. This organ is 
expected to harmonize efforts and activities undertaken by other institutions, to ensure that the policy is updated, and that implementation strategies and plans are drawn and carried out in the most efficient and effective manner. Currently, the e-government Agency is the coordinator of the implementation activities (E-Government Agency, 2014). A number of activities are coordinsated such as the registration of web addresses and government based emails. However, more coordination is required to the extent where public institutions will manage to utilize ICT tools in providing services online. Although the National ICT Policy acknowledges the importance of coordination, the lack of a legislative clause showing the line of accountability affects the process.

\section{Untimely Review of the ICT Policy and other Related Legislations}

The policy review cycle varies depending on the review scope. This study agrees with the comment by Lubua (2014), who identified two main reasons for changes in the ICT policy: These are changes in government's administrative focus and changes in technology. The analysis (by Lubua, 2014) proposed the review of the policy within a period not exceeding three years. The review within this period of time ensures that changes brought by the new technology are accommodated to the policy on time. Nevertheless, the Tanzanian National ICT policy existed for at least 10 years without a review. Many things have changed, which must be acknowledged by existing policies and legislations. At this point, the policy needs to be re-established to recognize newly established government agencies supporting its operation. Moreover, the National ICT Policy requires changes to address contemporary issues such as cyber security, information sharing rights, policy coordination, the line of accountability in policy implementation and the review its objectives.

\section{Low User Awareness}

Awareness is required for people to make the right decision on what method to use in acquiring services from government institutions. Unfortunately, even within the group of citizens who are aware of benefits associated with online services, many are not sure whether they can successfully access services through government online systems. Users admit that the use of online services depending on the support of government officers for response, is characterised by the unreliable response (Kihwelo, 2013; Lubua, 2014; Yonazi, Henk, \&Boonstra, 2010) . It's a common thing to use a mobile phone to complete a number of online transactions in the business sector, but the same can hardly be used in accessing services in government organizations. A good example is cited during the collection of the opinion of citizens for the new constitution; only $6.1 \%$ of opinions were collected through electronic means, while about $45 \%$ of Tanzanians owns at least a mobile phone (Draft Constitution Report, 2013).

\section{The Contribution of Regional Cooperations to the Effectiveness of ICT Legislations}

The East African Community (EAC) is among important co-operations, and it is worthy studying its contribution in influencing ICTs within the region. The EAC formulated a document for steering the development of its partners through ICTs. The document is known as the Protocol on Regional Information and Communication Technology (PRICT). Article 3.4 of the protocol requires member states to undertake necessary measures to harmonise legal issues to support the implementation and uses of ICTs in service provision. In Tanzania, the proposal by the protocol is valuable because of the presence of few legislative articles affecting the use of electronic information systems to share the information with the public.

Section 5 (1) of the Tanzanian Security Act of 1970, gives government officials the power to decide what government information is shared with citizens. In this part of the legislation, any person who communicates any classified matter to any person other than a person to whom he is authorized to communicate it shall be guilty of an offence. With such a protective article, government leaders withhold the information which would raise the awareness of citizens in the process of making informed decisions. For example, the inadvertent release of classified information (by opposition political leaders) about External Payment Arrears (EPA)and the ESCROW accounts of the central bank in 2009 and 2014 respectively, where billions of public funds were misused due to unethical decisions by government officials, brought a historical level of accountability to the nation. Unfortunately, unfaithful government leaders tend to use the prohibitive clause from the security act for both individual and political benefits. This habit is against the Constitution of Tanzania and other international treats that advocates maximum transparency and accountability in government activities.

The Tanzanian Newspapers Act of 1976 is another legislation, which requires the amendment to reflect the assertion by the PRICT. The Newspapers act affects effort for sharing the information about government business through media outlets. Section 25 (1) of the act grants the Minister of Information, the power to prohibit the publication of any Newspaper, if s/he is of the opinion that it is in the public interest or in the interest of peace and good order. The clause gives the government (and indeed the Minister) the power to assume two positions at the same time: A complainant and judge. Because of weaknesses in this law, the media outlets are victimised. In 2008 the Mwanahalisi Newspaper was completely banned, and both Mwananchi and 
Mtanzania were ordered not to publish for a period of 14 and 90 days respectively (Article19, 2013). The ban was for both printed and online copies. The law affects people who rely on newspapers to receive information about government business. As the result, citizens become less empowered for decision making.

Moreover, Article 9 of the PRICT proposed the establishment of the East African Community Directorate of Information and Communication Technologies (EACDICT). The main aim of this establishment is to coordinate the development and formulation of ICT policies in East Africa to meet society needs. Unfortunately, the directorate is not yet formulated.

Moreover, Tanzania is a member of another international platform known as the Open Government Partnership (OGP). Stakeholders of the forum advocate for open, accountable, and responsive government to citizens (Open Government Partnership, 2013). It is on the same basis that the Tanzanian government decided to launch a local Open Government Platform (OGP) that reflects these themes. Also, it aims to provide traditional government services through the use of ICTs. Other portals that reflect the OGP motives include: the E-Government Portal that provides government services online, The Recruitment Agency that provides employment opportunities within the government, and the Wananchi Portal, which receives complaints from citizens to different government (organs. Regardless of the presence of these infrastructures, the need for information sharing is not adequately addressed.

\section{CONCLUSIONS}

This study investigated the impact of policies and laws associated with the use of ICTs toward enhancing good governance. The study observed a number of efforts by the government of Tanzania in addressing policies that affect the implementation of ICTs. The efforts include the formulation of policies and legislations, which demonstrate the importance of using ICTs in government and business operations. Also, the efforts are demonstrated through establishing agencies which monitors the developments and uses of ICTs in the nation, and through participating in international collaborations which emphasize the need to use e-governance for enhanced developments.

Also, this study noted the presence of discussions (in different platforms) advocating changes to some legislative clauses perceived to inhibit the use of ICTs for enhanced governance of the people and resources. To a large extent, the laws affected operations of media outlet and granted excessive power to the government in matters pertaining information sharing. It is on this basis that the study recommends amendment to legislative articles that inhibits the use of ICTs for good governance. Particularly, the study recommends the improvement of section 10(1,2) of the Electronic and Postal Communication Act (CAP 306) of 2011 to make it mandatory for public oRrganisations to own a local website. The law must show how it addresses the question of relevance when it comes to web content, and the guideline for the use of the Swahili language.

Additionally, the study recommends the amendment of Section 5 (1) of the National Security Act No. 3 (1970), and Section 25 (1) of the Newspapers Act No. 3 (1976) to categorically remove restrictions to information sharing within the government. It is important to specify the type of information that would jeorpodise the National Security, to avoid the misuse of the clause in denying the information to citizens. Also, the study proposes the increase of the pace in formulating a new ICT policy. The new ICT policy must overcome challenges that come as the result of: The lack of coordinating structure and the lack of review. Additionally, the implementation of the East African Community protocol of ICT will harmonise policies by partner states to improve the pace of implementation and uses in government agencies.

\section{REFERENCES}

[1]. Article19. (2013). Tanzania: Newspapers banned amid increasing hostility towards free speech. Article19. Retrieved from https://www.article19.org/resources.php/resource/37273/en/tanzania:-newspapers-banned-amid-increasing-hostility-towards-freespeech

[2]. Bunge Maalumu la Katiba. (2013, December). TakwimuzaUkusanyajiwaMaoniyaWananchi. Retrieved December 3, 2014, from http://www.bungemaalum.go.tz/files/publications/attachments/TAKWIMU_ZA_UKUSANYAJI_WA_MAONI_YA_WANANCHI _sw.pdf

[3]. Collaboration on International ICT Policy in East and Southern Africa. (2012). How ICT Tools are Promoting Citizen Participation in Uganda. Retrieved December 2, 2014, from http://www.cipesa.org/?wpfb dl=38

[4]. Draft Constitution Report. (2013). TakwimuyaUkusanyajimaoniyawananchiKuhusuMabadilikoya Katiba yaJamhuriyaMuunganowa Tanzania. Dar Es Salaam: Government of Tanzania.

[5]. E-Government Agency. (2014). Who are we? Retrieved December 3, 2014, from http://www. ega.go.tz/index. php/ pages/page_details/6

[6]. Freedom House. (2010). Retrieved June 9, 2014, from http://www.freedomhouse.org/report/freedom-press/2011/tanzania\#. U5VtQfmSxzs

[7]. Internet Society. (2014). Global Internet Report. Retrieved June 30, 2014, from http://www.internetsociety.org/map/global-internetreport/?gclid=CLz1zdadob8CFQIewwodfU4AMg

[8]. Janssen, K. (2012). Open Government Data and the Right to Information: Opportunities and Obstacles. The Journal of Community Informatics, 8(2), 1-11

[9]. Kenya-Value Added Tax Act. (2013). Exemptions. Nairobi: Government of Kenya. 
[10]. Kihwelo, P (2013), Quality Assurance Systems in Open and Distance Learning: A Search for Normative Judgement. The Huria Journal. 14(1), 1-21

[11]. Kiknadze, G. (2007). E-Governance and e-Transparency. Tbilisi: Institute for Development of Freedom of Information.

[12]. Kowero, A. (2012). Exploiting the Potentials of the NICTBB in Tanzania. Dar Es Salaam: Tanzania Country Level Knowlege Network.

[13]. Lubua, E. (2014). Adoption of E-Transparency in the Public Sector of Tanzania. Durban: University of KwaZulu Natal.

[14]. Lubua, E., \&Maharaj, M. (2012). ICT Policy \& E-transparency in Tanzania Public Sector. IST-Africa 2012 Conference Proceedings. Dar es Salaam: IIMC International Information Management Corporation,.

[15]. Lupogo, I. (2014). Language of Instruction: A Challenge for Secondary Schools. Journal of Educational Policy and Entrepreneurial Research, 1(3), 26-30.

[16]. Mbarawa, M. (2012, January 27). ICT for Education -Mozambique, Tanzania. Retrieved November 29, 2014, from http://africanbrains.net/edusa/pdfs/Tanzania-Presentation.pdf

[17]. Nchunge, D. M., Sakwa, M., \& Mwangi, W. (2012). User's Perception on ICT Adoption For Education Support in Schools: A Survey of Secondary School Teacher's in Thika District Kenya. International Journal of Humanities and Social Science, Vol 2, No10.

[18]. oAfrica(2012). Household Internet speeds for 25 African countries. Retrieved January 20, 2014, from http://www. oafrica.com/broadband/household-internet-speeds/

[19]. Open Government Partnership. (2013). What is open Government Partnership. Retrieved June 16, 2014, from http://www.opengovpartnership.org/Tanzania ICT Policy. (2003). http://www.tzonline.org/pdf/ICTpolicy.pdf. Retrieved September 8, 2011, from http://www.tzonline.org/pdf/ICTpolicy.pdf

[20]. Tanzania National ICT Policy. (2003). National ICT Policy. Dar Es Salaam: The Government of Tanzania

[21]. The United Republic of Tanzania. (2012). Literacy and Education Monograph. Dar Es Salaam: Cencus.

[22]. Value Added Tax Act. (2006). Tax Exemptions. Dar Es Salaam: Government of Tanzania.

[23]. Yonazi, J., Henk, S., \&Boonstra, A. (2010). Exploring Issues Underlying Citizen Adoption of eGovernment Initiatives in Developing Countries: The Case of Tanzania. Electronic Journal of E-Government, 8(2), 176-188 